Article

\title{
Female CEOs and Corporate Innovation Behaviors-Research on the Regulating Effect of Gender Culture
}

\author{
Shuo Han ${ }^{1}$, Weijun Cui ${ }^{1,2, *}$, Jin Chen ${ }^{3,4}$ and $\mathrm{Yu} \mathrm{Fu}^{1}$ \\ 1 Business School, Nanjing University of Information Science \& Technology, Nanjing 210044, China; \\ jghs@nuist.edu.cn (S.H.); 20161263733@nuist.edu.cn (Y.F.) \\ 2 China Institute of Manufacturing Development, Nanjing University of Information Science \& Technology, \\ Nanjing 210044, China \\ 3 Research Center for Technological Innovation, Tsinghua University, Beijing 100084, China; \\ chenjin@sem.tsinghua.edu.cn \\ 4 School of Economics and Management, Tsinghua University, Beijing 100084, China \\ * Correspondence: cuiweijun@nuist.edu.cn
}

Received: 28 November 2018; Accepted: 23 January 2019; Published: 28 January 2019

\begin{abstract}
With the increasing number of female senior executives, the relationship between female senior executives and corporate innovation behaviors has attracted widespread attention, but few works have studied the influences of female CEOs on innovation behaviors and their mechanisms. This paper studies the relationship between CEO's gender and the selection of corporate innovation behaviors, as well as the regulating effect of gender culture on the relationship between them. It was discovered in the studies that (1) if compared with male CEOs, female CEOs have significantly promoted both incremental innovation behaviors and radical innovation behaviors; (2) gender culture has positively regulated the relationship between CEO's gender and corporate incremental innovation behaviors, yet the regulating effect of gender culture on the relationship between CEO's gender and corporate radical innovation behaviors is not significant. Thus, the government needs to further foster a gender culture with gender equality, and actively promote the positive effect of female CEOs in corporate innovations.
\end{abstract}

Keywords: gender culture; incremental innovations; radical innovations

\section{Foreword}

Under the backdrop of popular entrepreneurship and innovation in China, the influence of the gender of senior executives on corporate innovation decision-making and behavior has gradually emerged as a popular research topic. Generally speaking, it is generally believed among the academic community that risk preference of female senior executives is lower than that of male senior executives due to differences in growth and development patterns and personalities. Being more risk averse, female senior executives' innovation behaviors and performances are relatively low and adverse to corporate innovations. Existing research have also verified this point of view [1-3]. However, in recent years, on par with rapid socio-economic development, contradictions have surfaced with regards to existing facts, new research conclusions, and previous views on women.

First of all, in practice, female members in corporate management are playing increasingly important roles [4], and even breaking through the glass ceiling to the extent of starting to run their own businesses or being promoted to corporate CEOs. In China, the proportion of businesswomen in above-industry-designated-scale enterprises in China in 2017 was 20.4\% [5]. Enterprises above designated size are one of the commonly-used standards for measuring the scale of enterprises by 
the National Bureau of Statistics of China. They mainly refer to corporate industrial enterprises with annual income of RMB 20 million yuan or more. In contrast, this figure was more than $32.5 \%$ in micro-enterprises and even close to $80 \%$ in technology companies [5]. Micro-enterprises are also one of the commonly-used standards for measuring the scale of enterprises by the National Bureau of Statistics of China. They mainly refer to enterprises with less than 20 industrial employees or operating income of less than RMB 3 million yuan. The media believed that Chinese women were gaining high profiles in the technology industry, even surpassing that in the U.S.A [6]. There is no doubt that females have become an important factor affecting corporate governance. In addition, some female supervisors have broken through the ceiling and became corporate CEOs. Survey shows that new Internet companies created by women account for $55 \%$ of total, while the number of female entrepreneurs have exceeded one-quarter of the total [7]. As revealed in a report on China from the Globe Entrepreneurship Monitor (GEM), Chinese women entrepreneurs are more active than male entrepreneurs [8]. Furthermore, in terms of theoretical research, it has been found that female senior executives in different positions exert different influence on enterprise innovation. Existing studies have found that when female senior executives restrain corporate innovations, female CEOs have nevertheless relieved R\&D investment restraints imposed by female senior execs $[3,9]$. Therefore, female CEOs and ordinary female senior executives show different behavioral characteristics in corporate innovations, but there is lack of in-depth explorations with regard to this phenomenon.

Based on the above situation, the new question is how to treat and understand the influences of female CEOs on corporate innovations under the background that women have gradually broken through the ceiling and entered senior management, and even becoming female CEOs. First of all, in the decision-making process on corporate innovations, a CEO plays a key role as the main person in charge of enterprise operation and management, and also shoulders greater risks and responsibilities. For this reason, the CEO differs from general senior executives in terms of TOR (term of reference), accountability, and risk tolerance. Existing research mainly focus on the influence of the number of female senior executives has on corporate innovation behaviors, yet there is a lack of research on the influence of the leadership "quality" of female senior executives. That is to say, there are fewer studies that look at the difference between female CEO and general female senior executives, and female CEOs are studied only as moderating variables [3,9]. Therefore, there is a shortage of evidence to determine the relationship between female CEOs and corporate innovation behaviors. Secondly, existing research regarding the influence mechanism of female CEOs on corporate innovations remains insufficient, ignoring the role of gender culture. As a kind of social construction, behaviors of female CEOs are influenced by the whole society's opinions on women. Therefore, the more equal a society is, the more the possibility in stimulating female potentials and promoting corporate innovations. However, existing research has neglected the regulating effect of gender culture. Finally, as far as corporate innovation behaviors are concerned, incremental innovations are needed for continuous improvements in products, while radical innovations are required for new product development, market share acquisition, and profit improvement. Consequently, this paper focuses on the influence of CEO gender on incremental innovations and radical innovations in enterprises, and attempts to address the following two issues: (1) What are the innovation behaviors in companies where women serve as CEO, compared with scenarios in which men serve as CEO? (2) Has gender culture regulated the influence and effect of female CEOs on corporate innovation behaviors?

The basic structure of this paper is as follows. Firstly, relevant literature is reviewed, and research hypothesis is proposed on this basis. Secondly, an empirical model is constructed by matching data from the World Bank Survey of Chinese Manufacturing Enterprises with Chinese General Social Survey (CGSS), and the hypothesis is verified through an empirical analysis method. Upon this basis, further analysis of the internal mechanism of female CEOs on corporate innovation behaviors is conducted. Finally, research conclusions and policy recommendations are given. The main contributions of this paper lie in the studies on the influencing mechanism of gender culture on the relationship 
between CEO gender and corporate innovation behaviors, and supplementations to insufficiencies in current research.

\section{Literature Review and Research Hypothesis}

In the existing research, there present a greater difference and even opposite conclusion in the influences of female senior executives on corporate innovations. One view is that female senior executives have promoted corporate innovations $[10,11]$. While the other view is that female senior executives have hindered innovations [1,2].

The reasons for the emergence of contradictory situation mainly lie in the following two aspects. Firstly, in terms of research object, CEOs are studied as senior corporate executives in existing research, without careful differentiations between $\mathrm{CEO}$ and general senior executives. As a matter of fact, there are greater differences between $\mathrm{CEO}$ and general senior executives in terms of job levels and extent of power. In order to avoid business risks, general senior executives may tend to reduce innovation behaviors and shift the responsibility of innovation to CEOs, hence the slang of hitchhiking. Thus, in terms of research object, there is a need to pay close attention to CEOs assuming the main responsibility for corporate decision-making.

Secondly, from the perspective of research, the current research mainly focus on the perspective of female senior executives themselves, ignoring the circumstance in which female senior executives are in. On the one hand, the surrounding environment in which female senior executives work has been neglected, that is, the influences of many male senior executives on female senior executives. Existing research tends to assume that there are no differences between female senior executives and ordinary women, and the former population possesses the same traits of character as that of ordinary women, such as risk aversion, kindness, effective communication, etc. In this paper, such traits of character possessed by female senior executives in their lives are not denied. However, in the fierce market competition and complicated business management, influenced by many male senior executives around them, there is need to further analyze the particularity of female senior executives instead of simply 'copying' the traits of character of ordinary women to female senior executives. On the other hand, the general opinion towards women in society has been neglected, that is, the influence of gender culture on female senior executives. An implicit logical relationship often tends to be contained in the existing literature, "Because there are gender differences between male and female senior executives, their influences on corporate innovations are different." As a biological concept, sex is the objective difference that cannot be ignored. Furthermore, as a social construction, gender is the result of sex socialization, and also the subjective reflection of gender's objective reality influenced by the gender culture. In this paper, the behavioral differences between male and female senior executives in the process of corporate governance are considered as superficial phenomena, and their internal influences are outcomes of gender construction formed due to the interaction between gender and gender culture.

\subsection{CEO's Gender and Corporate Innovation Behaviors}

First of all, female CEOs promote corporate innovations because of the socialization and self-selection of women. In both life and work, women may undergo self-selections consciously or unconsciously. They compare themselves with groups of leaders or elites that they deem distinguished, identify the characteristics of the members of these groups that they want to surpass or pursue, and subsequently develop their vocational aspirations [12]. As a result, female CEOs tend to show masculine characteristics in the male-dominated environments under which they work extensively, and the essence of this change in characteristics lies in the socialization and self-selection of women. Existing studies also support the aforementioned viewpoint. Adams (2016) found in his studies that German women who choose to start a business usually have the same risk preference as that of men [13]. Vial (2016) and Hoyt et al. (2016) discovered that leadership styles and risk decisions among female senior executives are almost indistinguishable from that of male senior executives in 
male-dominated industries, mainly due to the reason that the existence of gender discrimination and prejudice cause female senior executives to have no choice but to imitate male senior executives in order to gain recognition and respect from their subordinates [14,15].

Secondly, another reason why female CEOs actively promote innovation is that existing evaluation mechanisms are not conducive to women. Decision-making is a relatively complex process [16], and female CEOs increase corporate value through innovation, thus realizing their own value. In the decision-making process, women are required to not only contemplate how to make a decision, but also how to deal with judgments from other people. Public judgment criteria for men and women are also different, as reflected in the inclination to look to future performance in men, versus more focus on the past and present performance in women [17]. As such, the existing performance and feedback-based corporate promotion mechanism is disadvantageous to female senior executives [18]. In the dynamic feedback process, the results of gender bias may accumulate over time. Ultimately, women are more likely to quit leadership positions when compared with men, and thus there is a lower possibility for women to be identified as leaders. That is to say, as a kind of retention mechanism, feedback itself is more likely to benefit men rather than women. The primary purpose that drives female entrepreneurs is to prove their own value and realize the meaning of life [19]. Therefore, women have to invest more efforts than men and achieve more results for the company, so as to gain recognitions and realize their life's value. Positive innovation behaviors can bring about better results thus more recognition for female CEOs.

Thirdly, female CEOs actively promote corporate innovations also because of their unique human capital advantages. Although female CEOs tend to be masculine, it does not mean that their female personality characteristics are totally lost. Moreover, advantages inherent in female senior executives may also promote corporate innovations. Because of different personal experience compared with men, women tend to have more distinct traits and characteristics such as emotional sensitivity, acute and strong intuition, risk-taking and innovative spirit, outstanding communication and social skills, and strong sense of responsibility [20]. These gender differences are conducive when deliberating and dealing with problems. Female senior executives may make full use of their professional experiences, ways of thinking, emotional preferences or other attributes formed in previous work, and provide innovative perspectives and new problem-solving methods in decision-making and corporate management. These new thoughts and viewpoints from women are precisely the prerequisites for technological innovations [11]. Existing research also support this point of view. From the perspective of innovation process, as the saying goes, "a mix of Jacks and Jills makes a tough job a breeze" (or mixed gender increases efficiency at workplace). The participation of female senior executives is helpful to change the gender structure of a company, which is beneficial to the formation of a good innovation atmosphere and the promotion of technological innovations [11]. In terms of innovation results, in a highly competitive market environment, the rise in the number of women in the corporate senior executive team may indicate that this company is increasingly likely to become a leader in the industry, and that this company can launch new products earlier and quicker than competitors [21]. From the perspective of promoting innovation, an increase in the number of female senior executives may facilitate a company's market expansion efforts, help expand potential customers, and enhance understanding of market and customers [22,23].

Therefore, this paper proposes the below research hypotheses:

H1a: Female CEOs have promoted corporate incremental innovations;

H1b: Female CEOs have promoted corporate radical innovations.

\subsection{Regulating Effect of Gender Culture}

The influence of gender culture on people is imperceptible, far-reaching and long-lasting. Just as famously remarked by Simone de Beauvoir, the earliest authoritative theorist of the modern women's movement, "one is not born a woman, but becomes one (On ne naît pas femme, on le deviant) [24]", 
which intends to emphasize the far-reaching influence of gender culture on women, that is to say, women are the result of social construction and the product of social gender. In a certain social culture and situation, gender culture leads to differences in attitudes, behaviors, social status and other aspects between men and women, thus forming the society's understanding and cognition of 'masculinization' and 'feminization', and also regulating and defining the behavioral patterns of both sexes [25]. In the same social culture and situation, all members within the society will be influenced by such culture and situation, enabling the behaviors of men and women to be regulated and leading to similar behaviors in the same sexes. In the long run, a cumulative effect may be generated in individuals both psychologically and physiologically, thus forming a closed loop of reciprocal effect between sex and gender culture [26]. Gender culture also produces normative concepts through social customs and habits, and subsequently defines the social status and behavioral norms of both sexes in public and private spheres [27]. In certain regions of China, it is a prevalence belief that "marrying a good husband is better than getting a good job" [28]. Women often give up their careers and are forced to resign due to the pressure or obligation to bear children [29]. Therefore, the influence of gender culture on women has profound social significance, and thus deserves further study.

In the current gender culture in which men and women tend to be equal, gender culture is less and less restrictive on women. In other words, the more women are liberated, the more achievements women would accomplish. Since the founding of New China, a large number of outstanding women have emerged in various fields such as scientific research, business management, fine arts and many others, which is a phenomenon unimaginable in feudal society. In terms of family relationship, the more equal a society treats the genders, the more possible and acceptable it would before women to share housework with men, consequently reducing family conflicts [30]. In terms of demands for female CEOs, when gender culture is more equal, social demands for female CEOs will increase. On the contrary, when gender culture is unequal, social demands for female CEOs will in turn decrease [31]. In corporate management, when women leaders possess more legitimacy, access to resources, opportunities in education, participation in the economy, employment and political rights, they will more actively influence corporate strategy and performance [32]. In summary, the equality of gender culture and the tolerance of women are directly proportional to the formation and display of female managerial competence. On the contrary, gender culture discrimination and disrespect for women are inversely related to the formation and display of female managerial competence.

Therefore, this paper proposes the following research hypotheses:

H2a: Gender culture positively regulates the relationship between female CEOs and incremental innovation behaviors of enterprises. The more equal gender culture is, the more beneficial it will be for female CEOs to carry out incremental innovations.

H2b: Gender culture positively regulates the relationship between female CEOs and radical innovation behaviors of enterprises. The more equal gender culture is, the more beneficial it will be for female CEOs to carry out radical innovations.

\section{Model Constructions and Variable Design}

\subsection{Data Sources}

Empirical data in this paper are sourced from World Bank Questionnaire on Chinese Enterprises 2012 and Chinese General Social Survey (CGSS) 2012.

The selection of World Bank China Enterprise Questionnaire Data in 2012 is based on following three main reasons: Firstly, the availability of data. Micro data at the corporate level are difficult to be obtained by the public in China, and this is the latest data publicly available from the World Bank Survey of Chinese Enterprises. Secondly, in terms of sample selection, the reason why the data of listed companies are not selected in this paper is that non-listed companies make up the majority of the Chinese market. As of 2016, there are 3337 enterprises on the Shanghai and Shenzhen 
Stock Exchanges, while there are actually 87.054 million companies existing as various types of market entities throughout China [33]. Thus, the proportion of listed companies in China is relatively low compared with the total number of market entities in China, and non-listed companies occupy the lion's share of market entities. Thirdly, if compared with non-listed companies, Chinese listed companies have better corporate governance characteristics and better system. Therefore, based on the comprehensive consideration of the make-up of market entities and corporate governance conditions, the World Bank China Enterprise Questionnaire Data in 2012 can more objectively reflect the influence of CEO gender on corporate innovations in Chinese enterprises on the whole. From December 2011 to February 2013, the World Bank conducted a stratified sampling survey method and investigated 2848 enterprises in 23 cities throughout 12 provinces (cities) including Beijing City, Shanghai City and Guangdong Province (The provinces and cities mainly involved in the World Bank's 2012 survey include Beijing, Shanghai, Guangdong: Guangzhou, Shenzhen, Foshan, Dongguan, Anhui: Hefei, Hebei: Shijiazhuang, Tangshan, Henan Province: Zhengzhou City, Luoyang City, Hubei Province: Wuhan City, Jiangsu Province: Nanjing City, Wuxi City, Suzhou City, Nantong City, Liaoning Province: Shenyang City, Dalian City, Shandong Province: Jinan City, Qingdao City, Yantai City Sichuan Province: Chengdu, Zhejiang Province: Hangzhou, Ningbo, Wenzhou), including 2700 private enterprises and 148 state-owned enterprises. This survey provides the aforementioned enterprises' data and additional information for one complete accounting year.

In order to ensure the accuracy of data on gender culture, more authoritative and accurate data from the China General Social Survey (CGSS) have been selected for use in this paper. The data were selected for the following two reasons: First of all, CGSS data can guarantee authoritativeness. Founded in 2003 and implemented by Renmin University of China, CGSS is the earliest nationwide, comprehensive and continuous academic investigation program in China. In accordance with international standards, since 2003 CGSS has conducted continuous cross-sectional survey of more than 10,000 households in Chinese provinces, municipalities, and autonomous regions every year. CGSS systematically and comprehensively collects data from multiple levels of society, community, family, and individual, summarizes the trends of social changes, probes into issues of great scientific and practical significance, promotes the opening and sharing of scientific research in China, and provides data for international comparative research. As a multidisciplinary economic and social data collection platform, CGSS has published more than 1000 academic journals based on its own data. In 2007, it represented China and became a member of the International Social Survey Program (ISSP), and now serves as a window for China to carry out international exchanges and cooperation in social survey. Besides, CGSS data can match the World Bank survey data. CGSS provides data from all provinces, municipalities and autonomous regions in mainland China, including the sample of cities surveyed by the World Bank. However, and unfortunately, due to confidentiality requirements, CGSS data only publish the province-level information of its samples, and does not publish information about sampled prefecture-level cities. Therefore, the variable of gender culture in this paper reflects only the overall viewpoint of residents in corresponding provinces towards women.

\subsection{Sample Cleaning}

In order to better conduct research, this paper screens and processes raw data from the World Bank, and the main steps are as follow: (1) Consider the match between questionnaire and sample, and delete observation data labeled "No, does not match" according to questionnaire question A5 (Question A5: Sector match between screener information and sample frame, three options are given: 1. Yes, screener and sample frame info match; 2 . No, screener and sample frame do not match but establishment still does activities which match sample frame; 3. No, does not match.); (2) Due to the difference in the governance model between parent company and subsidiary company, consider sample comparability, and delete subsidiary companies with the answer "YES" according to questionnaire question A7 (Question A7: Establishment is part of a larger firm? Two options are given: 1. Yes; 2. No, a firm on its own.); (3) With consideration to the validity of data, delete observations with 
answers labeled "not truthful" and "are arbitrary and unreliable numbers" according to questionnaire questions A16 (Question A16: It is my perception that the responses to the questions regarding opinions and perceptions, three options are given: 1 . Truthful; 2. Somewhat truthful; 3. Not truthful) and A17 (Question A17: The responses to the questions regarding figures (productivity and employment numbers). Three options are given: 1 . Are taken directly from establishment records; 2 . Are estimates computed with some precision; 3 . Are arbitrary and unreliable numbers); (4) For sake of prudence, missing values from all variables are deleted from all models, and replacement is not done in any way. Thus, there are a total of 1033 observations in one incremental innovation model, and a total of 1036 observations in two radical innovation models.

The treatment process of CGSS data in this paper is as follows: (1) delete missing value observations that did not answer corresponding question; (2) calculate average by province with regard to issues reflecting gender culture A423 (Question A423 in CGSS: Do you agree with the following statements: A good husband is better than a good job? Four answers are provided for such question: "Completely disagree", "Partially disagree", "It doesn't matter whether to agree or disagree"; "Partially agree", "Completely agree"), that is, sample data of the same province is summarized and averaged, and such mean value will be used to measure the level of gender culture in corresponding province.

\subsection{Models}

In order to verify the influence of CEO gender on corporate innovation behaviors and the regulating effect of gender culture, a regression model needs to be set up in this paper. In the observations used for sample in this paper, the number of female CEOs is relatively small, accounting for $7 \%$ of the total sample. This issue also exists in the available literature, but it has little effect on regression analysis results [34,35]. Therefore, the regression models of this paper are:

Model 1: $y_{1}=\alpha_{0}+\alpha_{1}$ Gender $+\alpha_{2}$ Culture $+\gamma_{1} \sum x_{i}+\varepsilon_{1}$

Model 2: $y_{2}=\beta_{0}+\beta_{1}$ Gender $+\beta_{2}$ Culture $+\gamma_{2} \sum x_{i}+\varepsilon_{2}$

Of these, $y_{1}$ represents incremental innovation behaviors, and $y_{1}$ represents radical innovation behaviors, Gender represents the core variable of CEO gender, Culture represents regional gender culture, $x_{i}$ represents control variable, $\alpha_{0}, \beta_{0}$ represent constant terms, $\varepsilon_{1}, \varepsilon_{2}$ represent random error terms.

\subsection{Variables}

In this paper, two different types of corporate innovation behaviors, i.e., incremental innovation and radical innovation, are taken as explained variables. Characteristics of female CEOs and market competition are taken as explanatory variables. Enterprise characteristics, regional characteristics and industry characteristics are set as controlled variables. For details, please see Table 1.

\subsubsection{Explained Variables}

In past research and practices, the low success probability in innovation results from the fact that work classification is neglected in many strategies and management methods [36]. In fact, corporate innovations require both incremental innovations supplemented by discontinuous innovations, so as to meet today's ever-changing customer needs. For this reason, two different kinds of innovation behaviors, namely, discontinuous radical innovations and incremental innovations, are selected in this paper for comparative research. In the design of variables, since it is difficult to define incremental and radical innovations, their meanings can only be defined by using themselves [37]. In past research, scholars mainly take the occurrence of incremental innovation behaviors and the existence of radical innovation behaviors as measurement standards [38]. Therefore, corporate technological innovation behaviors are taken as the measurement standard in this paper. 
Table 1. Design and description of variables.

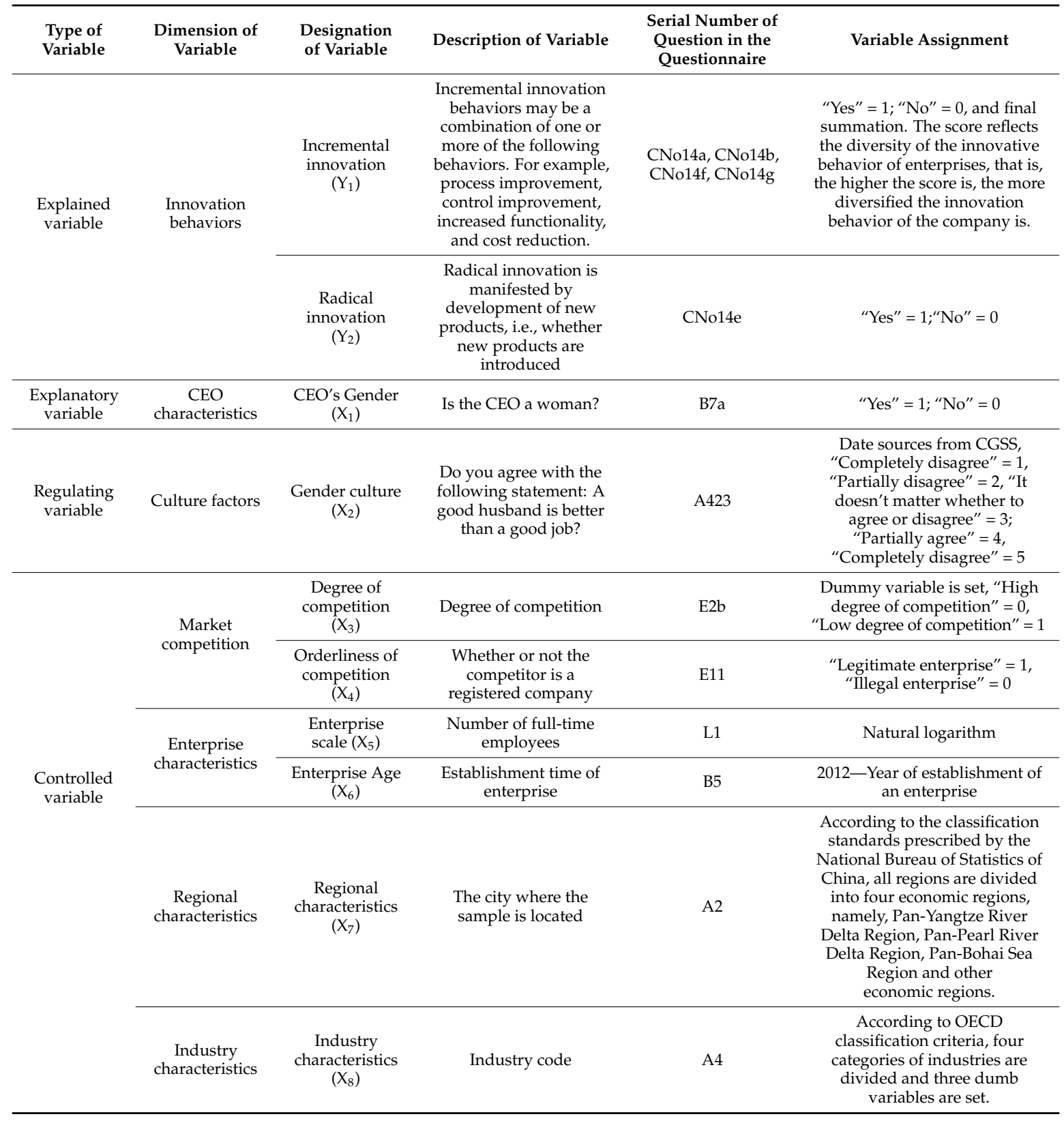

(1) In terms of incremental innovation behaviors, many such actions-including process improvement, product quality improvement, cost reduction, increased functionality, and reduced energy consumption - may be included. Thus, incremental innovation behaviors can be a combination of one or more of the above. In order to reflect the overall level of incremental innovations, it is necessary to summate and assign values based on the above various innovation behaviors. Referring to existing literature [38,39], incremental innovation behaviors can be identified according to question CNO.14 options such as CNO.14a, CNO.14b, CNO.14f, CNO.14g (CNO.14: Over the last three years (2009-2011), what type of innovation activities has this establishment engaged in? CNO.14a: Introduce new technology and equipment(s) for product or process improvements, CNO.14b: Introduce new quality control procedure in production or operations, CNO.14f: Add new features to existing products or services, CNO.14g: Take measures to reduce production cost). In this case, one score will be obtained if there is one of the above innovation behaviors, and a score of 0 if there is no innovation of any kind. Next, scores will be summed. The higher score an enterprise obtains, the more incremental 
innovation behaviors said enterprise will perform. The score reflects the diversity of exploitative innovation behavior.

(2) As for radical innovation, it is mainly based on whether new products are being introduced. Therefore, according to the question CNO.14 (CNO.14e: Introduce new product or new service) and its option CNO.14e, " 0 " and " 1 " are set as dummy variables, with the introduction of new product assigned a " 1 " and no introduction of new product given a " 0 ".

Thus, any radical innovation behavior will be assigned a " 1 " while no radical innovation behavior will be given a " 0 ".

\subsubsection{Explanatory Variables}

According to previous analysis, $\mathrm{CEO}$ gender variable is established in this paper. According to question B7a (B7a: Is the Top Manager female?), if the answer is "YES", it indicates that the CEO of this company is female. Thus, the value assigned will be " 1 ", otherwise, the value given will be " 0 ".

\subsubsection{Regulating Variable}

Gender culture is established as regulating variable in this paper, and gender culture reflects the overall viewpoint towards women and the gender equality relationship. In certain regions of China, it is a prevalence belief that "marrying a good husband is better than getting a good job" [28]. Women often give up their careers and are forced to resign due to the pressure or obligation to bear children [29]. This shows that gender culture has a far-reaching impact on women.

In terms of the measurement method for gender culture, attitude towards marriage is taken as an indicator for measurement of gender culture in this paper mainly because of reasoning from the following three aspects: First of all, since antiquity the predominant image of an ideal Chinese women is that of a "dutiful wife and loving mother", thus closely binding Chinese women, marriage and family together. Therefore, marriage and family are an important part of gender culture, and it is inappropriate to indulge in empty talk about gender culture by isolating marriage from family. Secondly, the improvement of women's social status begins with the family. Before the founding of New China, women did not have independent social status and could not participate in social activities, and husband's requests were the wife's standard of measurement and code of conduct. After the founding of New China, the government got rid of feudal remnants and re-established the status of women in the household. As a result, women can actively participate in all aspects of the society. Thirdly, the success of women in corporate management is inseparable from family support. In this paper, for a woman to become a CEO is considered a success, and to further promote corporate innovations, equality, family, and marriage is even more inseparable.

In terms of assigning value to this variable, this paper refers to relevant literature [28,40]. According to question A423 in the questionnaire and its options (Question A423 in CGSS: Do you agree with the following statements: A good husband is better than a good job? Four answers are provided for such question: "Completely disagree", "Partially disagree", "It doesn't matter whether to agree or disagree"; "Partially agree", "Completely agree".), the configurations for values are listed as below, "Completely agree" $=1$, "Partially agree" = 2, "It doesn't matter whether to agree to disagree" = 3; "Partially agree" $=4$, "Completely agree" $=5$. The higher the score of this variable, the lower the degree of equality, and vice versa.

\subsubsection{Controlled Variables}

In this paper, market competition, enterprise characteristics, regional characteristics and industry characteristics are established as controlled variables.

(1) Market competition: Market competition is complicated, manifested by the number and degree of differences of competitors in the external environment [41]. First of all, the number of competitors essentially reflects the intensity of competition. Thus, the variable of degree of competition is established in this paper. According to question E2b (Question E2b: In fiscal year 2011, for the 
main market in which this establishment sold its main product, how many competitors did this establishment's main product face? Options given: 1 . Number of competitors; 2 . Too many to count), previous studies divided the quantity of competitors into "countless competitors" and "specific number of competitors" [39]. In reality, where there are competitors, there will be competition. Therefore, in order to facilitate understanding, it is feasible to interpret "a specific number of competitors" as a low degree of competition, and in this case the value of 1 is assigned. "Countless competitors" is interpreted as a high degree of competition, and in this case the value of 0 is assigned. Secondly, in terms of the degree of differences between competitors, ordinal variables are established in this paper. According to contents in the questionnaire (Question E11: Does this establishment compete against unregistered or informal firms? Option to be given: Yes or No), legally registered enterprise is given the value " 1 ", while non-legally registered enterprise is assigned a value of " 0 ".

(2) Enterprise characteristics: There are major differences in the operating behaviors of enterprises in different industries. By referring to existing research on Chinese enterprises [42], two main variables are established in this paper, namely enterprise scale and enterprise age.

(3) Industry characteristics: Classification is arranged by referring to the technology intensity of industry according to OECD.

(4) Regional characteristics: According to classification criteria prescribed by the National Bureau of Statistics of China, total area is divided into four economic regions, namely, the Pan-Yangtze River Delta Region, Pan-Pearl River Delta Region, Pan-Bohai Sea Region, and other economic regions. Specifically, the Pan-Yangtze River Delta Region includes the sample areas of Shanghai, Nanjing, Wuxi, Suzhou, Nantong, Hefei, Hangzhou, Ningbo and Wenzhou. The Pan-Pearl River Delta Region includes the sample areas of Guangzhou, Shenzhen, Foshan and Dongguan. The Pan-Bohai Sea Region includes the sample areas of Beijing, Shijiazhuang, Tangshan, Jinan, Qingdao and Yantai. The Other Economic Regions include Zhengzhou, Luoyang, Wuhan, Shenyang, Dalian and Chengdu.

The specific settings of variables are shown in Table 1.

\section{Descriptive Statistical Analysis}

\subsection{Distribution Characteristics of CEO Gender and Corporate Innovation Behaviors}

CEO gender and corporate innovation behaviors are respectively shown in the figures below, so as to visually express their relationships. The distribution characteristics of female CEOs and incremental innovation behaviors are shown in Figure 1, while the distribution characteristics of female CEOs and radical innovation behaviors are shown in Figure 2. The green column indicates the proportion of female CEOs in all CEOs within that region. The higher the green column is, the higher proportion of female CEOs within that region. The red column indicates the ratio of enterprises performing innovation behaviors in all enterprises within that region. The higher the red column is, the more innovation behaviors performed in that region.

As far as the distribution characteristics of female CEOs are concerned, if observed from south to north (In China, Qinling-Huaihe River is often used as the North-South boundary line. In this paper, southern samples include Shanghai, Nanjing, Wuxi, Suzhou, Nantong, Hefei, Hangzhou, Ningbo, Wenzhou, Guangzhou, Shenzhen, Foshan, Dongguan, Wuhan, and Chengdu. Northern samples include Beijing, Shijiazhuang, Tangshan, Jinan, Qingdao, Yantai, Zhengzhou, Luoyang, Shenyang, and Dalian, the same below.), the evident trend is that there are more female CEOs in the south than there are in the north. Moreover, there are obviously more female CEOs in the Yangtze River Delta than in the Pearl River Delta. 


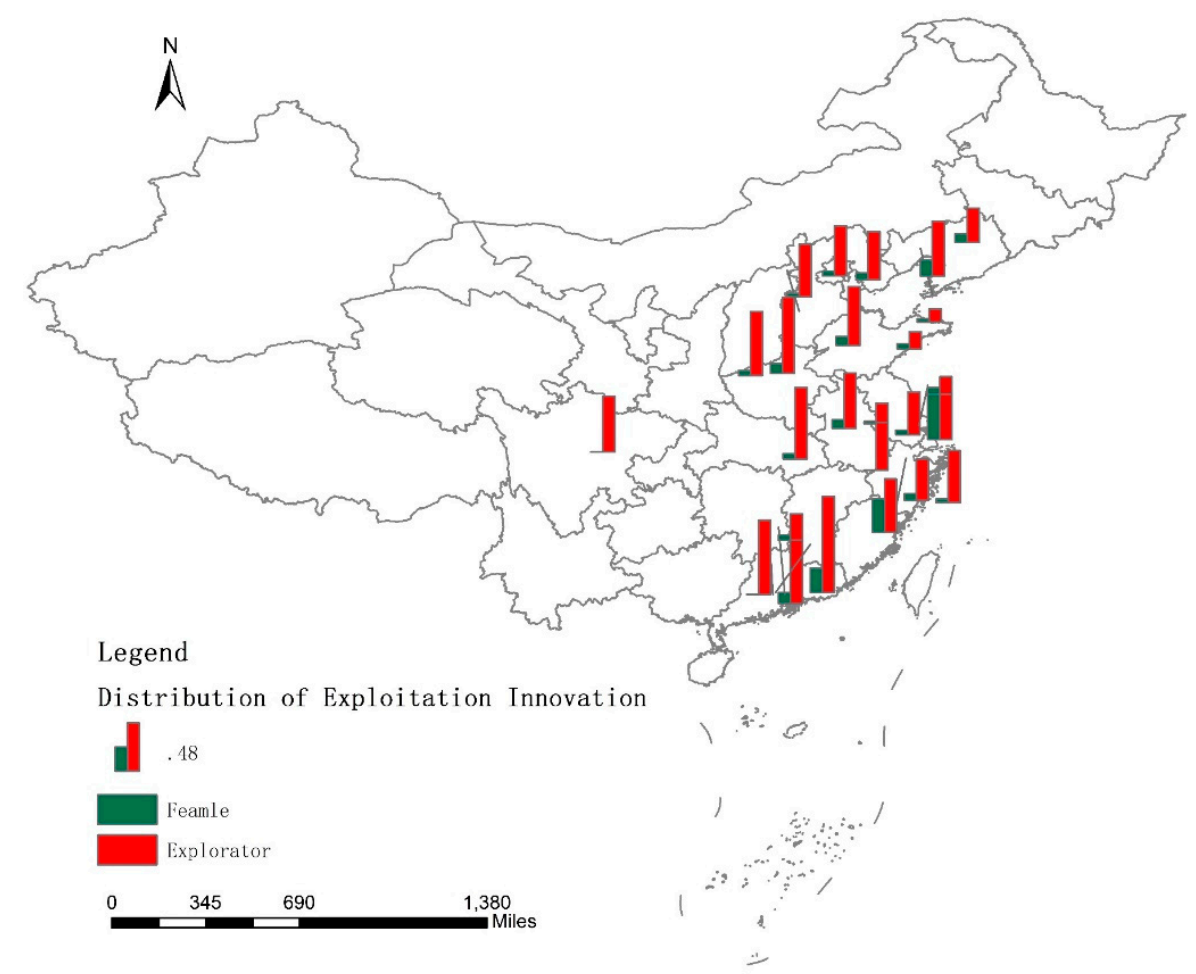

Figure 1. Distribution of female CEOs and incremental innovations.

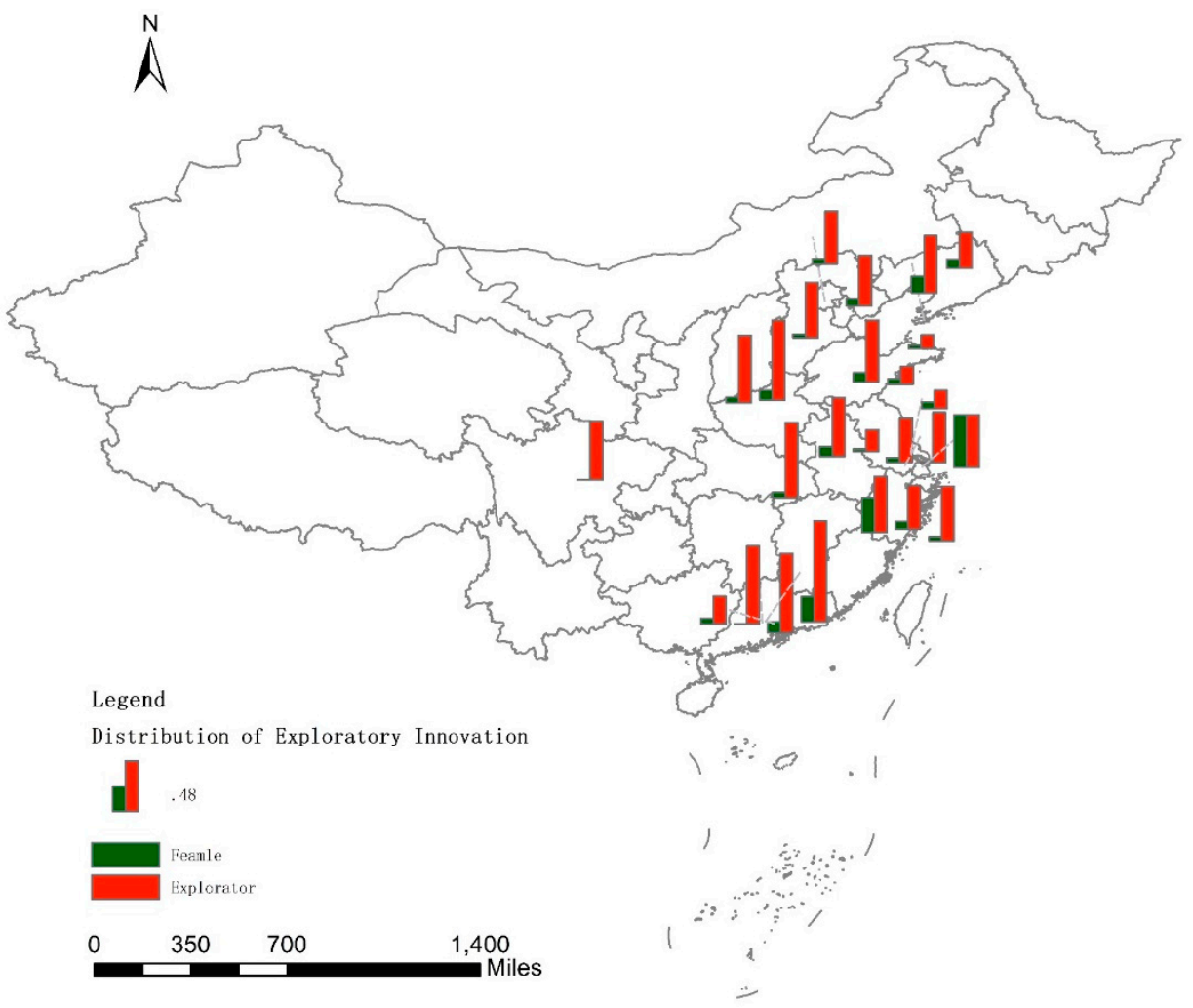

Figure 2. Distribution of female CEOs and radical innovations.

In the east-west direction, China can be divided into three parts, i.e., east, middle, and west. The eastern part in this paper mainly refers to the eastern coastal areas of China, the central part mainly refers to the areas adjacent to the hinterland of the Central Plains, and the western area mainly refers to the provinces where western development policy is implemented. Samples from eastern region 
include Shanghai, Nanjing, Wuxi, Suzhou, Nantong, Hefei, Hangzhou, Ningbo, Wenzhou, Guangzhou, Shenzhen, Foshan, Dongguan, Beijing, Jinan, Qingdao, Yantai, Shenyang and Dalian. Samples from the central region include Wuhan, Shijiazhuang, Tangshan, Zhengzhou, and Luoyang. The western region mainly includes Chengdu, the same below. If observed from east to west, the evident trend is that there are more female CEOs in eastern coastal region than there are in the central and western regions. As far as corporate innovation behaviors are concerned, if observed from south to north, there are more innovation behaviors in the south than there are in the north. If observed from east to west, there are more innovation behaviors in the east than there are in the west. Therefore, the overall pattern is that there are more corporate innovation behaviors in southern China than there are in northern China, and there are more corporate innovation behaviors in the eastern part of the country than the western part. To sum up, there is distribution consistency between female CEOs and corporate innovation behaviors.

\subsection{Incremental Innovation Behaviors}

The results of sample statistics are shown in Table 2. In this model, there are a total of 1033 observations. (1) In terms of incremental innovations, the mean value is 2.220 and the full range is 4 , which indicates that enterprises have performed some degree of incremental innovation behaviors, yet there is still room for improvement in this regard. (2) In terms of gender of senior executives, there are 74 female CEOs, accounting for $7.616 \%$ of total, and the mean value of female CEOs is 0.072 , as in one female out of every 13 to 14 CEOs, indicating that the number of female CEOs is relatively few and the CEO position is male-dominated. (3) In terms of market competition, the mean value of the degree of competition is 0.150 , indicating that most enterprises face $a$ high level of fierce competition. In terms of the orderliness of competition, the mean value is 0.431 , indicating that most enterprises have to face illegal competitors. Thus, as a whole, enterprises are facing greater market competition risks and greater market competition pressure. (4) In terms of enterprise characteristics, the mean value of enterprise size is 69.130 persons, and the mean value of enterprise age is 12.947 years.

Table 2. Statistical table of corporate incremental innovation behaviors.

\begin{tabular}{cccccc}
\hline Variable & Sample Size & Minimum Value & Maximum Value & Mean Value & $\begin{array}{c}\text { Standard } \\
\text { Deviation }\end{array}$ \\
\hline Incremental innovation & 1033 & 0.000 & 4.000 & 2.220 & 1.462 \\
CEO's gender & 1033 & 0.000 & 1.000 & 0.072 & 0.258 \\
Gender culture & 1033 & 2.830 & 3.513 & 3.174 & 0.190 \\
Degree of competition & 1033 & 0 & 1 & 0.150 & 0.357 \\
Orderliness of & 1033 & 0 & 1 & 0.431 & 0.495 \\
competition & 1033 & 5 & 16,000 & 69.130 & 1.220 \\
Enterprise scale & 1033 & 0 & 125 & 12.947 & 7.644 \\
Enterprise age & & &
\end{tabular}

\subsection{Radical Innovation Behaviors}

The descriptive statistical results of corporate radical innovation behavior model are shown in Table 3. (1) In terms of radical innovation behaviors, the mean value is 0.490 , indicating that nearly half of the sampled enterprises have performed radical innovation behaviors. (2) In terms of CEO gender, the mean value is 0.070 , which means that one in every 14 to 15 CEOs is female, indicating that female CEOs account for a relatively low proportion. (3) In terms of gender culture, the mean value is 3.174, indicating that the vast majority of people hold prejudice against women and there exists inequality between men and women. (4) In terms of competition, the mean value of the degree of competition is 0.150 , and the mean value for the orderliness of competition is 0.431 , indicating that enterprises have to face high level of fierce competition and that they have to face illegal competitors. (5) In terms of enterprise characteristics, the mean value of enterprise size is 69.130 persons, and the mean value of enterprise age is 12.953 years. 
Table 3. Descriptive statistical table of corporate radical innovation behaviors.

\begin{tabular}{cccccc}
\hline Variable & Sample Size & Minimum Value & Maximum Value & Mean Value & $\begin{array}{c}\text { Standard } \\
\text { Deviation }\end{array}$ \\
\hline Radical innovation & 1036 & 0.000 & 1.000 & 0.490 & 0.500 \\
CEO's gender & 1036 & 0.000 & 1.000 & 0.070 & 0.256 \\
Gender culture & 1036 & 2.830 & 3.513 & 3.174 & 0.190 \\
Degree of competition & 1036 & 0 & 1 & 0.151 & 0.358 \\
Orderliness of competition & 1036 & 0 & 1 & 0.430 & 0.495 \\
Enterprise scale & 1036 & 5 & 16,000 & 69.130 & 1.221 \\
Enterprise age & 1036 & 0 & 125 & 12.953 & 7.640 \\
\hline
\end{tabular}

\section{Empirical Analysis}

\subsection{Correlation Analysis and Multicollinearity Test}

In Tables 4 and 5, correlation analysis and VIF test results are shown. As for the core variable of CEO gender, female CEOs have significantly positive impact on incremental innovations and radical innovations, signifying that there are strong correlations between female CEO and these two types of innovations, yet further tests remain to be conducted. In the process of using cross-section data, the multicollinearity between variables may exert influence on regression results. Thus, multicollinearity needs to be excluded. Judging from the correlation coefficient test of explanatory variables, the absolute values of correlation coefficients in each variable are basically less than 0.5. Moreover, the variance expansion factor (VIF) test also shows that VIF values of the core explanatory variables and control variables are less than 10 , the critical criterion for multicollinearity. Therefore, there is no need to worry too much about the influence of multicollinearity on regression results.

Table 4. Correlation analysis and VIF test of incremental innovation behaviors.

\begin{tabular}{|c|c|c|c|c|c|c|c|}
\hline & $\begin{array}{l}\text { Incremental } \\
\text { Innovations }\end{array}$ & $\begin{array}{l}\text { CEO's } \\
\text { Gender }\end{array}$ & $\begin{array}{c}\text { Degree of } \\
\text { competition }\end{array}$ & $\begin{array}{l}\text { Orderliness of } \\
\text { Competition }\end{array}$ & $\begin{array}{l}\text { Enterprise } \\
\text { Scale }\end{array}$ & $\begin{array}{l}\text { Enterprise } \\
\text { Age }\end{array}$ & $\begin{array}{l}\text { VIF } \\
\text { Test }\end{array}$ \\
\hline $\begin{array}{l}\text { Incremental } \\
\text { Innovations }\end{array}$ & 1.0000 & & & & & & - \\
\hline CEO's gender & $0.0738 * *$ & 1.0000 & & & & & 1.01 \\
\hline Gender culture & $0.0945^{* * *}$ & $0.0620 * *$ & 1.0000 & & & & 1.02 \\
\hline $\begin{array}{l}\text { Degree of } \\
\text { competition }\end{array}$ & -0.0104 & -0.0294 & $0.0998^{* * *}$ & 1.0000 & & & 1.02 \\
\hline $\begin{array}{l}\text { Orderliness of } \\
\text { competition }\end{array}$ & $0.2504^{* * *}$ & $-0.0569 *$ & 0.0172 & $0.0971^{* * *}$ & 1.0000 & & 1.06 \\
\hline Enterprise scale & $0.0660 * *$ & -0.0138 & -0.0336 & 0.0368 & $0.2116^{* * *}$ & 1.0000 & 1.05 \\
\hline
\end{tabular}

Table 5. Correlation analysis and VIF test of radical innovation behaviors.

\begin{tabular}{|c|c|c|c|c|c|c|c|}
\hline & $\begin{array}{c}\text { Radical } \\
\text { innovation }\end{array}$ & $\begin{array}{l}\text { CEO's } \\
\text { Gender }\end{array}$ & $\begin{array}{l}\text { Degree of } \\
\text { competition }\end{array}$ & $\begin{array}{l}\text { Orderliness of } \\
\text { Competition }\end{array}$ & $\begin{array}{l}\text { Enterprise } \\
\text { Scale }\end{array}$ & $\begin{array}{c}\text { Enterprise } \\
\text { Age }\end{array}$ & $\begin{array}{l}\text { VIF } \\
\text { Test }\end{array}$ \\
\hline $\begin{array}{c}\text { Radical } \\
\text { Innovations }\end{array}$ & 1.0000 & & & & & & - \\
\hline CEO's gender & $0.1223^{* * *}$ & 1.0000 & & & & & 1.01 \\
\hline Gender culture & $0.1323^{* * *}$ & 0.0528 * & 1.0000 & & & & 1.01 \\
\hline $\begin{array}{l}\text { Degree of } \\
\text { competition }\end{array}$ & $-0.0710^{* *}$ & -0.0332 & $0.0981^{* * *}$ & 1.0000 & & & 1.02 \\
\hline $\begin{array}{l}\text { Orderliness of } \\
\text { competition }\end{array}$ & $0.1524^{* * *}$ & $-0.0546 *$ & 0.0252 & $0.1035^{* * *}$ & 1.0000 & & 1.06 \\
\hline Enterprise scale & 0.0235 & -0.0131 & -0.0320 & 0.0386 & $0.2138 * * *$ & 1.0000 & 1.05 \\
\hline
\end{tabular}

\subsection{Regression Analysis of CEO's Gender and Corporate Innovation Behaviors}

In this paper, STATA 14.0 is used to conduct empirical analysis. In order to reduce the influence of heteroscedasticity, robust standard error is adopted in the regression analysis of this paper. Due to 
the low proportion of female CEOs ( $7.6 \%$ in this paper), this problem is found universally in existing literature [34,35], and there is not yet a good solution to this problem. For the selection of specific model, regression method from existing literature is referenced $[38,39,43]$. Specifically, the OLS method is utilized for incremental innovations, and Logit model adopted for radical innovations. The influence of CEO gender on corporate incremental innovations and radical innovations are displayed in Table 6. Model 1 and Model 2 are generally significant.

Table 6. Main empirical results.

\begin{tabular}{ccc}
\hline Variable & Incremental Innovations & Radical Innovations \\
\cline { 2 - 3 } & Model 1 & Model 2 \\
\hline CEO's gender & $0.456^{* * *}$ & $1.083^{* * *}$ \\
Degree of competition & $(2.71)$ & $(3.95)$ \\
Orderliness of competition & $0.442^{* * *}$ & $0.878^{* * *}$ \\
Enterprise scale & $(3.46)$ & $(4.48)$ \\
Enterprise age & -0.0900 & $-0.287^{*}$ \\
& $(-0.97)$ & $(-1.93)$ \\
Constant term & $0.282^{* * *}$ & $0.267^{* * *}$ \\
Industry characteristics & $(7.93)$ & $(4.74)$ \\
Regional characteristics & 0.00461 & 0.00399 \\
F & $(0.71)$ & $(0.45)$ \\
R2 & $0.576^{* * *}$ & $-1.838^{* * *}$ \\
Root MSE & $(3.19)$ & $(-6.46)$ \\
Chi2 & Control & Control \\
Pseudo R2 & Control & -- \\
Log-likelihood & $19.43^{* * *}$ & - \\
$\mathrm{N}$ & 0.131 & -- \\
Nontrol & 1.371 & $116.57^{* * *}$ \\
\hline
\end{tabular}

Note: ${ }^{* * *}, * *$, and $*$ are respectively significant at $1 \%, 5 \%$, and $10 \%$ levels. In the model for incremental innovations, the number in brackets is the $t$ value of the double-tailed test. In the model for radical innovations, the number in brackets is the $\mathrm{Z}$ value of the double-tailed test.

For the core variable of CEO gender, when compared with male CEOs, female CEOs have significantly promoted both corporate incremental and radical innovation behaviors, assuming that $1 \mathrm{a}$ and $1 \mathrm{~b}$ are verified. There are three primary reasons why female CEOs have been able to drive both incremental and radical innovation behaviors. Firstly, due to influences of the external environment, female CEOs tend to show masculine characteristics, which is mainly attributed to socialization and self-selection of women. Secondly, existing performance appraisal system is unfavorable to women, and thus in order to achieve better performance, female CEOs attempt to win the market through innovations. Finally, because of women's unique human capital advantages, when compared with male CEOs, female CEOs are more adept at communication and observation, which enable them to maximize team strength and instigate an active approach to innovations. Of course, this is a kind of correlation rather than causal relationship. Thus, there could be other explanations.

In terms of control variables, (1) influences of market competition on corporate innovation behaviors are more complicated. The degree of competition has dramatically raised both incremental innovation behaviors and radical innovation behaviors. Judging from coefficients, the degree of competition has greater influence on corporate radical innovations than on incremental innovations. The reason mainly lies in the fact that the more fierce the competition is, the greater the necessity is to improve product quality and enhance business performance through innovations. In terms of the orderliness of competition, for legitimate enterprises, the negative influence of the orderliness of competition on corporate incremental innovations is insignificant. In contrast, the negative influence of 
the orderliness of competition on corporate radical innovations is significant. This may have been the effect of the following two causes. For one thing, competitors are illegal enterprises whose corporate behaviors circumvent or ignore legal restraints. For another, radical innovations have augmented product improvements, and such improvements are more easily and cheaply copied or replicated. Thus, the more radical innovations, the bigger the damage to an enterprise. Studies of Blazsek $\mathrm{S}$, Escribano A., et al. [44] also supported the above viewpoint. (2) Enterprise size has significantly promoted corporate innovation behaviors, primarily because larger enterprises have more capacity to strengthen innovations. (3) Enterprise age does not have much influence on enterprise innovation behaviors. (4) In terms of industry characteristics, hi-tech enterprises are more prominent in performing innovation behaviors, indicating that hi-tech companies are more willing to and capable of innovation. (5) In terms of regional characteristics, enterprises in the Bohai Rim Region and other economic regions are more prone to undertake innovation behaviors.

\subsection{Regression Analysis Considering the Regulating Effect of Gender Culture}

In order to verify the regulating effect of gender culture, this paper conducted an interactive regression between CEO gender and gender culture, and the regression results of interaction term are displayed in Table 7. In order to reduce the influence of heteroscedasticity, robust regression analysis is still applied in the regression model. The OLS method is adopted for incremental innovations, and Logit regression analysis used for radical innovations. Model 3 and Model 4 are generally significant.

Table 7. Main empirical results.

\begin{tabular}{|c|c|c|}
\hline \multirow{2}{*}{ Variables } & Incremental Innovations & Radical Innovations \\
\hline & Model 3 & Model 4 \\
\hline CEO's gender & $\begin{array}{c}5.155 * \\
(1.88)\end{array}$ & $\begin{array}{l}0.385 \\
(0.08)\end{array}$ \\
\hline Gender culture & $\begin{array}{c}0.932^{* * *} \\
(3.01)\end{array}$ & $\begin{array}{l}-0.247 \\
(-0.46)\end{array}$ \\
\hline CEO's gender * Gender culture & $\begin{array}{l}-1.474 * \\
(-1.71)\end{array}$ & $\begin{array}{l}0.222 \\
(0.14)\end{array}$ \\
\hline Degree of competition & $\begin{array}{c}0.447^{* * *} \\
(3.48)\end{array}$ & $\begin{array}{c}0.879 * * * \\
(4.49)\end{array}$ \\
\hline Orderliness of competition & $\begin{array}{l}-0.0775 \\
(-0.84)\end{array}$ & $\begin{array}{l}-0.290 * \\
(-1.95)\end{array}$ \\
\hline Enterprise scale & $\begin{array}{c}0.287^{* * *} \\
(8.08)\end{array}$ & $\begin{array}{c}0.266^{* * *} \\
(4.73)\end{array}$ \\
\hline Enterprise age & $\begin{array}{c}0.00447 \\
(0.68)\end{array}$ & $\begin{array}{c}0.00401 \\
(0.45)\end{array}$ \\
\hline Constant term & $\begin{array}{c}-2.332 * * \\
(-2.39)\end{array}$ & $\begin{array}{l}-1.070 \\
(-0.63)\end{array}$ \\
\hline Industry characteristics & Control & Control \\
\hline Regional characteristics & Control & Control \\
\hline $\mathrm{F}$ & $17.32^{* * *}$ & -- \\
\hline $\mathrm{R} 2$ & 0.140 & -- \\
\hline Root MSE & 1.365 & -- \\
\hline Chi2 & -- & $116.44^{* * *}$ \\
\hline Pseudo R2 & -- & 0.0962 \\
\hline Log-likelihood & -- & -648.833 \\
\hline $\mathrm{N}$ & 1033 & 1036 \\
\hline
\end{tabular}

Note: ${ }^{* * *}, * *$ and * are respectively significant at $1 \%, 5 \%$, and $10 \%$ levels. In the model of incremental innovations, the number in brackets is the $t$ value of the double-tailed test. In the model of radical innovations, the number in brackets is the $\mathrm{Z}$ value of the double-tailed test.

In terms of incremental innovations, CEO gender, gender culture, and interaction terms have significant influence on incremental innovations. CEO gender has significant influence on incremental 
innovations, manifested by the increase of coefficient from 0.456 to 5.155 , an increase of 11.305 times. With regards to interaction term, there is significant negative influence in the interaction terms of CEO gender and gender culture, and this negative influence is mainly derived from values assigned to variable. That is to say, the more unequal gender culture, the higher the scores. Thus, a higher degree of equality in gender culture means more beneficial circumstance for improvement in corporate incremental innovation behaviors, assuming that $\mathrm{H} 2 \mathrm{a}$ is verified. However, in terms of radical innovations, CEO gender, gender culture, and interaction terms do not have much influence on corporate radical innovation behaviors.

One possible explanation for this result is that the existing gender culture lags behind the level of economic development, and this gender culture is insufficient to support women to carry out a greater degree of innovations. From the perspective of leadership, different leaders often share common features that have little to do with gender [45], but they may engender bigger differences in corporate innovation behaviors, thus it is necessary to consider the influence of gender culture on such features. Gender culture has given rise to normative concepts through customs and habits, consequently defining social status and behavioral norms of both sexes in both public space and private areas [27]. However, people usually classify themselves and others according to their attributes. Different social classes or groups are expected to behave differently by default, and there are costs to be borne if an individual's behaviors were to deviate from the default expectations of the social group in which said individual belongs, which would then affect said individual's economic behaviors and outputs [46].

Judging from the internal meaning and external impact of innovation behaviors, incremental innovation is a kind of progressive innovation and imparts a lesser degree of disruption to the existing environment. In contrast, radical innovation is a kind of non-progressive and non-continuous innovation that breaks through existing restraints, and imparts a greater degree of disruption to the existing environment. Under the backdrop of the current gender culture, discriminations against women in employment still take place, and backward mentalities such as valuing men over women and chauvinism are still in play, which are invisible shackles that hamper the innovation behaviors of female CEOs. Only when women become aware of their existence as independent and complete entities, as well as the equality between them and men, can the effectual role of women be stimulated and the inner potential in women be harnessed and activated to the maximal extent. Subjective consciousness is the internal motivation behind women's all-round developments. The strength of subjective consciousness in women is directly proportional to their degree of self-realization and the level of their contribution to societal progress [29]. At the same time, role models will have an important impact on the evolution of culture and future career development [47]. Therefore, a woman's career development will be affected by the overall gender culture. Culture is generally assumed to evolve rather slowly [48]. It is evident that gender culture in today's society lags behind the current level of economic development and is insufficient to instigate the awakening of self-awareness and subjective consciousness in women. Therefore, gender culture and its interaction terms have insignificant influence on corporate radical innovations, but significant influence on corporate incremental innovations.

\section{Robustness Test}

In light of the availability of data, the gender culture factor in this paper is defined as a provincial-level reflection of society's overall attitude towards women. Therefore, the influence of female CEOs on corporate innovation behaviors may not change the overall gender culture of the whole society, but on the contrary, the gender culture of the whole society may affect the extent of influence female CEOs have on corporate innovation behaviors. That is to say, gender culture in this paper is an exogenous variable. Thus, the endogenous problem in this model is solved, but the robustness test still needs to be performed. In this paper, the robustness test is conducted through the application of three methods, namely sample distribution, sample bias, and replacement of method. 


\subsection{Considerations on the Influence of Sample Distribution on Empirical Results}

According to Note 20, in the sample there are 19 observations distributed in the eastern coastal region, five observations in the central region, and one observation in the western region. Thus, observations are mainly concentrated in the eastern region. In order to eliminate the influence caused by uneven regional distribution of observations, the dummy variable of "Eastern Observations" is established in this paper, defining observations in the eastern coastal area as 1, and observations in other areas as 0 . In addition, interaction terms of gender and eastern samples are also established. Similarly, in order to lower the influence of heteroscedasticity, robust regression analysis is adopted in regression analysis. Empirical results are shown in Model 5-8 of Table 8. Judging from the empirical results, the model is generally significant, but the influence of the interactivity of variables in eastern observations and genders do not have a significant influence on corporate innovation behaviors, thus eliminating the influence of the relatively eastern region-dominated concentration on empirical results.

Table 8. Main empirical results.

\begin{tabular}{|c|c|c|c|c|}
\hline \multirow{2}{*}{ Variables } & \multicolumn{2}{|c|}{ Incremental Innovations } & \multicolumn{2}{|c|}{ Radical Innovations } \\
\hline & Model 5 & Model 6 & Model 7 & Model 8 \\
\hline CEO's gender & $\begin{array}{c}0.455 * * * \\
(2.71)\end{array}$ & $\begin{array}{l}0.379 \\
(1.10)\end{array}$ & $\begin{array}{c}1.096^{* * *} \\
(4.00)\end{array}$ & $\begin{array}{c}1.293 * * \\
(2.19)\end{array}$ \\
\hline Eastern samples & $\begin{array}{c}-0.0608 \\
(-0.40)\end{array}$ & $\begin{array}{l}-0.0682 \\
(-0.43)\end{array}$ & $\begin{array}{c}0.0272 \\
(0.12)\end{array}$ & $\begin{array}{c}0.0453 \\
(0.19)\end{array}$ \\
\hline CEO's gender * Eastern samples & $\begin{array}{l}-- \\
--\end{array}$ & $\begin{array}{c}0.0976 \\
(0.25)\end{array}$ & $\begin{array}{l}-- \\
--\end{array}$ & $\begin{array}{l}-0.251 \\
(-0.38)\end{array}$ \\
\hline Degree of competition & $\begin{array}{c}0.444^{* * *} \\
(3.48)\end{array}$ & $\begin{array}{c}0.444^{* * *} \\
(3.48)\end{array}$ & $\begin{array}{c}0.188 \\
(1.22)\end{array}$ & $\begin{array}{l}0.189 \\
(1.23)\end{array}$ \\
\hline Orderliness of competition & $\begin{array}{l}-0.0932 \\
(-1.00)\end{array}$ & $\begin{array}{l}-0.0927 \\
(-0.99)\end{array}$ & $\begin{array}{c}0.858^{* * *} \\
(4.36)\end{array}$ & $\begin{array}{c}0.856^{* * *} \\
(4.35)\end{array}$ \\
\hline Enterprise scale & $\begin{array}{c}0.282^{* * *} \\
(7.94)\end{array}$ & $\begin{array}{c}0.282^{* * *} \\
(7.92)\end{array}$ & $\begin{array}{c}-0.266 \text { * } \\
(-1.77)\end{array}$ & $\begin{array}{l}-0.267^{*} \\
(-1.78)\end{array}$ \\
\hline Enterprise age & $\begin{array}{c}0.00457 \\
(0.70)\end{array}$ & $\begin{array}{c}0.00457 \\
(0.70)\end{array}$ & $\begin{array}{c}0.263 * * * \\
(4.66)\end{array}$ & $\begin{array}{c}0.264^{* * * *} \\
(4.67)\end{array}$ \\
\hline Constant term & $\begin{array}{c}0.638^{* * *} \\
(2.65)\end{array}$ & $\begin{array}{c}0.645^{* * * *} \\
(2.67)\end{array}$ & $\begin{array}{c}0.000604 \\
(0.07)\end{array}$ & $\begin{array}{c}0.000591 \\
(0.07)\end{array}$ \\
\hline Regional characteristics & Control & Control & Control & Control \\
\hline Industry characteristics & Control & Control & Control & Control \\
\hline $\mathrm{F}$ & $17.89^{* * *}$ & $16.55^{* * *}$ & -- & -1 \\
\hline $\mathrm{R} 2$ & 0.1311 & 0.1311 & -- & -- \\
\hline Root MSE & 1.3712 & 1.3719 & -- & -- \\
\hline Chi2 & -- & -- & $117.70^{* * *}$ & $117.73^{* * *}$ \\
\hline Pseudo R2 & -- & -- & 0.0971 & 0.0972 \\
\hline Log-likelihood & -- & -- & -648.21008 & -648.14231 \\
\hline Sample size & 1033 & 1033 & 1036 & 1036 \\
\hline
\end{tabular}

Note: ${ }^{* * *}, * *$, and ${ }^{*}$ are respectively significant at $1 \%, 5 \%$, and $10 \%$ levels. In the model of incremental innovations, the number in brackets is the $t$ value of the double-tailed test. In the model of radical innovations, the number in brackets is the $\mathrm{Z}$ value of the double-tailed test.

\subsection{Considerations on the Influence of Sample Deviations}

In the sample of this study, the total proportion of women is relatively small. Therefore, propensity score matching (PSM) is applied to in this paper, so as to eliminate the influence of sample deviations. At the same time, in order to lower the influence of heteroscedasticity, robust standard error is adopted in the regression analysis of this paper. Empirical results are exhibited in Table 9. Judging from the results, relevant tests are all significant. Thus, the influence of sample deviations can be excluded. 
Table 9. Main empirical results.

\begin{tabular}{ccc}
\hline Variables & Incremental Innovations & Radical Innovations \\
\hline \multirow{2}{*}{ ATT } & $0.781^{* * *}$ & $0.264^{* * *}$ \\
& $(2.73)$ & $(2.65)$ \\
ATU & $0.576^{* *}$ & $0.285^{* * *}$ \\
& $(2.54)$ & $(3.80)$ \\
ATE & $0.591^{* * *}$ & $0.283^{* * *}$ \\
Sample size & $(2.73)$ & $(3.97)$ \\
\hline
\end{tabular}

\subsection{Consideration on the Replacement of Method}

In the robustness test, the replacement of the model method is also a common approach. For incremental innovations, truncated Poisson regression model is used. For radical innovations, Probit model is applied. At the same time, in order to reduce the influence of heteroscedasticity, robust standard error is adopted in the regression analysis of this paper. Empirical results are reported in Table 10. Judging from the empirical results, Models 9 through 12 are generally significant. If compared with Models 1 to 4, coefficient sizes have slightly changed, yet significance remains unchanged. Empirical results support the main conclusions of this paper.

Table 10. Main empirical results.

\begin{tabular}{|c|c|c|c|c|}
\hline \multirow{2}{*}{ Variables } & \multicolumn{2}{|c|}{ Incremental Innovations } & \multicolumn{2}{|c|}{ Radical Innovations } \\
\hline & Model 9 & Model 10 & Model 11 & Model 12 \\
\hline CEO's gender & $\begin{array}{c}0.200 * * * \\
(3.06)\end{array}$ & $\begin{array}{c}2.287^{* *} \\
(2.05)\end{array}$ & $\begin{array}{c}0.666^{* * *} \\
(4.04)\end{array}$ & $\begin{array}{l}0.510 \\
(0.18)\end{array}$ \\
\hline Degree of competition & $\begin{array}{c}0.191 \text { *** } \\
(3.66)\end{array}$ & $\begin{array}{c}0.194^{* * * *} \\
(3.69)\end{array}$ & $\begin{array}{c}0.531^{* * * *} \\
(4.49)\end{array}$ & $\begin{array}{c}0.533^{* * *} \\
(4.51)\end{array}$ \\
\hline Legitimacy of competition & $\begin{array}{l}-0.0391 \\
(-0.94)\end{array}$ & $\begin{array}{c}-0.0362 \\
(-0.87)\end{array}$ & $\begin{array}{l}-0.170 * \\
(-1.91)\end{array}$ & $\begin{array}{l}-0.172 \text { * } \\
(-1.93)\end{array}$ \\
\hline Enterprise scale & $\begin{array}{c}0.124^{* * *} \\
(8.01)\end{array}$ & $\begin{array}{c}0.127 * * * \\
(8.17)\end{array}$ & $\begin{array}{c}0.166^{* * *} \\
(4.81)\end{array}$ & $\begin{array}{c}0.165^{* * *} \\
(4.79)\end{array}$ \\
\hline Enterprise age & $\begin{array}{c}0.00182 \\
(0.70)\end{array}$ & $\begin{array}{c}0.00173 \\
(0.66)\end{array}$ & $\begin{array}{c}0.00246 \\
(0.45)\end{array}$ & $\begin{array}{c}0.00248 \\
(0.46)\end{array}$ \\
\hline Gender culture & & $\begin{array}{c}0.464^{* * * *} \\
(2.85)\end{array}$ & & $\begin{array}{l}-0.151 \\
(-0.48)\end{array}$ \\
\hline CEO's gender * Gender culture & & $\begin{array}{c}-0.654 * \\
(-1.85)\end{array}$ & & $\begin{array}{c}0.0499 \\
(0.06)\end{array}$ \\
\hline cons & $\begin{array}{c}0.0521 \\
(0.61)\end{array}$ & $\begin{array}{c}-1.397^{* * * *} \\
(-2.73)\end{array}$ & $\begin{array}{c}-1.140 * * * \\
(-6.54)\end{array}$ & $\begin{array}{l}-0.672 \\
(-0.67)\end{array}$ \\
\hline Industry characteristics & Control & Control & Control & Control \\
\hline Regional characteristics & Control & Control & Control & Control \\
\hline Chi2 & $203.69 * * *$ & $210.76^{* * *}$ & $127.12^{* * *}$ & $127.37^{* * *}$ \\
\hline Pseudo R2 & 0.0337 & 0.0362 & 0.0960 & 0.0962 \\
\hline Log pseudolikelihood & -1788.1921 & -1783.5433 & & \\
\hline Log-likelihood & & & -648.97325 & -648.84577 \\
\hline $\mathrm{N}$ & 1033 & 1033 & 1036 & 1036 \\
\hline
\end{tabular}

Note: ${ }^{* * *}, * *$, and $*$ are respectively significant at $1 \%, 5 \%$, and $10 \%$ levels. The number in brackets is the $Z$ value of the double-tailed test.

\section{Conclusions and Discussion}

A rising number of women are promoted into corporate executive positions, but there are not many literatures that analyze the influence of female CEOs on corporate innovation behaviors or relevant underlying mechanisms. In this paper, data from the World Bank Survey of Chinese Manufacturing Enterprises 2012 and data from Chinese General Social Survey (CGSS) are coupled, a model of the influence of CEO gender on corporate innovation behaviors under conditions of gender 
culture is constructed, and the relationship between CEO gender and corporate innovation behaviors, as well as the regulating effect of gender culture in this relationship, are studied.

\subsection{Conclusions}

The research results show that (1) if compared with male CEOs, female CEOs have significantly promoted corporate incremental innovation behaviors and radical innovation behaviors; and (2) gender culture has regulated the relationship between CEO gender and corporate incremental innovation behaviors. The more equal the gender culture is, the more beneficial the climate will be for female CEOs to carry out incremental innovations. Gender culture and corporate radical innovation behaviors have no regulating effect.

\subsection{Implications}

In this paper, the authors explore, from the perspective of gender culture, the differences and influence mechanism affecting female senior executives and male senior executives in innovation decision-making process, enriching currently available literature and providing valuable insights beneficial to corporate management practices.

Firstly, this study shows that female senior executives are contributive to corporate innovations. The essence at the core of promoting innovation is a human resource-driven approach. As an important role in technological innovation, female innovators function as an inexhaustible force that drives innovation [49]. For this reason, in corporate management practices, the value of women value should be respected. In the course of the selection of senior executives, women and men should be given equal opportunities and treated under the same conditions, so that a larger number of excellent and capable women can partake in corporate management. In certain regions of China, it is a prevalent belief that "marrying a good husband is better than getting a good job" [28]. Women often give up their careers and are forced to resign due to the pressure or obligation to bear children. The logic behind this situation is to deny the value of women, and refuse to recognize or considerably depreciate the value of women in their childbearing and household duties [29]. Thus, there is a need to affirm and respect the value of women in management practice, actively incorporate more women into senior management, take the initiative in capitalizing on the advantages of female CEOs with regards to innovation, and foster conditions for women to help companies develop competitive advantages beneficial to sustainable development.

Secondly, this study shows that the current gender culture has failed to keep pace with economic development, which weakens the ability for female CEOs to implement radical innovation behaviors. This paper believes that women and men have their respective advantages in corporate management, but the backward gender culture in China impedes women's management capabilities. As a kind of cultural phenomenon, gender culture lags behind and slows down economic development. In this regard, all sectors of the society should actively engender a more advanced gender culture characterized by increased equality between men and women, regard women as a kind of human resource, provide development opportunities to and create sound development climate for women, and enable women to fully develop their potentials and subsequently realize their full value.

Thirdly, in terms of innovation behaviors, female CEOs are more innovative than other female executives. It is generally believed that women's risk preference is lower than that of men, thus inhibiting innovations. However, this paper has found that because of the influences of the external environment, female CEOs acquire others' recognitions through their innovations. Therefore, along with the gradual climb in the number of female CEOs, the academic circle ought to reevaluate female CEOs and understand them from a brand new perspective.

\subsection{Shortcomings and Prospects}

In this paper, there are still some shortcomings in the following regards. Firstly, due to the limitations of data availability, the proportion of female CEOs in the entire sample is relatively low. 
Meanwhile, the gender culture data provided by CGSS is only limited to provincial-level data, and there was no access to gender culture data at the corporate level. Secondly, the influence mechanism through which female CEOs promote corporate innovation behaviors mandates further analysis, such as other factors in addition to gender culture. Thus, for future research, the recommendation is to consider increasing the sample data of female CEOs, so that intrinsic influence mechanisms can be further studied and the accuracy and depth of research can also be enhanced.

Author Contributions: Conceptualization, W.Z.C. and J.C.; Data curation, S.H.; Funding acquisition, W.Z.C.; Methodology, S.H.; Project administration, W.Z.C. and J.C.; Visualization, S.H.; Writing-original draft, S.H., W.Z.C., and Y.F.; Writing—review and editing, S.H. and Y.F.

Funding: This research was funded by The Philosophy and Social Sciences outstanding innovation team construction project of Jiangsu Province (No. 2015ZSTD006), The Development report of philosophy and social sciences of Ministry of education of China (No.13JBG004), Postgraduate Research \& Practice Innovation Program of Jiangsu Province.

Conflicts of Interest: The authors declare no conflicts of interest.

\section{References}

1. Strohmeyer, R.; Tonoyan, V.; Jennings, J.E. Jacks-(and Jills)-of-all-trades: On whether, how and why gender influences firm innovativeness. J. Bus. Ventur. 2017, 32, 498-518. [CrossRef]

2. Quintana-García, C.; Benavides-Velasco, C.A. Gender Diversity in Top Management Teams and Innovation Capabilities: The Initial Public Offerings of Biotechnology Firms. Long Range Plan. 2016, 49, 507-518. [CrossRef]

3. Wang, Q.; Zhou, Z. Female Executives and R\&D Investment: Empirical Evidence China. Manag. World 2015, 3, 178-179. (In Chinese)

4. Xu, X.; Li, Y. Executive gender, system environment and enterprise CSR decision. Sci. Res. Manag. 2018, 39, 80-89. (In Chinese)

5. China Statistics Publishing House. China Enterprise Innovation Survey Yearbook; China Statistics Publishing House: Beijing, China, 2017. (In Chinese)

6. Lacy, S. Women in Tech Are Rising Higher in China Than in the U.S. Available online: https://www. theatlantic.com/technology/archive/2017/11/women-china-tech/545588/?platform=hootsuite (accessed on 28 January 2019).

7. Liang, J. The Business World should create More Rising Paths for Women. Available online: http://www. sohu.com/a/128260831_460419 (accessed on 28 January 2019). (In Chinese)

8. Xinhuanet Global Entrepreneurship Watch's Report on China: Women Entrepreneurs are Increasingly Active. Available online: http:/ /www.xinhuanet.com/fortune/2016-01/28/C_128679968.htm (accessed on 28 January 2019). (In Chinese)

9. $\mathrm{Mu}, \mathrm{D}$. The role of female executives in R \& D investment decisions-An Empirical Study Based on China's A share listed companies. Luojia Manag. Rev. 2016, 2, 22-35. (In Chinese)

10. Jiménez, J.M.R.; Fuentes, M.D.M.F. Management capabilities, innovation, and gender diversity in the top management team: Ann empirical analysis in technology-bases SMEs. Bus. Res. Q. 2016, 19, 107-121. [CrossRef]

11. Zeng, P.; Wu, Q. The impact of female top management participation on Technological Innovation: An Empirical Study Based on GEM companies. Stud. Sci. Sci. 2012, 30, 773-781. (In Chinese)

12. Vianen, A.E.M.V.; Fischer, A.H. Illuminating the glass ceiling: The role of organizational culture preferences. J. Occup. Organ. Psychol. 2011, 75, 315-337. [CrossRef]

13. Adams, R.B. Women on boards: The superheroes of tomorrow? Leadersh. Q. 2016, 27, 371-386. [CrossRef]

14. Vial, A.C.; Napier, J.L.; Brescoll, V.L. A bed of thorns: Female leaders and the self-reinforcing cycle of illegitimacy. Leadersh. Q. 2016, 27, 400-414. [CrossRef]

15. Hoyt, C.L.; Murphy, S.E. Managing to clear the air: Stereotype threat, women, and leadership. Leadersh. Q. 2016, 27, 387-399. [CrossRef]

16. Zhang, N.; Gong, Z.; Yin, K.; Wang, Y. Special Issue “Decision Models in Green Growth and Sustainable Development". Int. J. Environ. Res. Public Health 2018, 15, 1093. [CrossRef] [PubMed]

17. Huston, T. How Women Decide; HMH: Boston, MA, USA, 2016. 
18. Bear, J.B.; Cushenbery, L.; London, M.; Sherman, G.D. Performance feedback, power retention, and the gender gap in leadership. Leadersh. Q. 2017, 28, 721-740. [CrossRef]

19. Li, L.; Zhong, W.; Wang, Y. The development of Chinese Female Entrepreneurs: Current situation, problems and expectations-A survey of 2505 female entrepreneurs. Manag. World 2017, 11, 50-64. (In Chinese)

20. Eagly, A.H. Female leadership advantage and disadvantage: Resolving the contradictions. Psychol. Women Q. 2007, 31, 1-12. [CrossRef]

21. Srivastava, A.; Lee, H. Predicting order and timing of new product moves: The role of top management in corporate entrepreneurship. J. Bus. Ventur. 2005, 20, 459-481. [CrossRef]

22. Carter, D.A.; D'Souza, F.; Simkins, B.J.; Simpson, W.G. The gender and ethnic diversity of US boards and board committees and firm financial performance. Corp. Gov. Int. Rev. 2010, 18, 396-414. [CrossRef]

23. Carter, D.A.; Simkins, B.J.; Simpson, W.G. Corporate governance, board diversity, and firm value. Financ. Rev. 2003, 38, 33-53. [CrossRef]

24. De Beauvoir, S.; Parshley, H.M. The Second Sex; Alfred A. Knopf, Inc.: New York, NY, USA, 1953.

25. Spence, J.T.; Helmreich, R.; Stapp, J. Ratings of self and peers on sex role attributes and their relation to self-esteem and conceptions of masculinity and femininity. J. Personal. Soc. Psychol. 1975, 32, $29-39$. [CrossRef]

26. Chen, $\mathrm{J} . ; \mathrm{Wu}, \mathrm{X}$. The theoretical connotation and application of gender Innovation-The contribution of sex and gender analysis. Soc. Sci. Front 2018, 4, 67-74, 281. (In Chinese)

27. Yang, J. The continuity and change of Chinese concept of gender in the past 20 years. Sociol. Res. 2017, 11, 60-71. (In Chinese)

28. Xiong, A.; Wang, Z.; Zhang, Y.; Li, H. Gender heterogeneity and corporate decision making: A comparative study from a cultural perspective. Manag. World 2018, 6, 127-139. (In Chinese)

29. Lv, H. Construction of gender culture and harmonious development of both sexes. J. Hebei Univ. (Philos. Soc. Sci.) 2007, 32, 1-4. (In Chinese)

30. Nelson, D.L.; Burke, R.J. Women executives: Health, stress, and success. Acad. Manag. Perspect. 2000, 14, 107-121. [CrossRef]

31. Wang, G.; Holmes, R.M.; Devine, R.A.; Bishoff, J. CEO gender differences in careers and the moderating role of country culture: A meta-analytic investigation. Organ. Behav. Hum. Decis. Process. 2018, 148, 30-53. [CrossRef]

32. Post, C.; Byron, K. Women on boards and firm financial performance: A meta-analysis. Acad. Manag. J. 2015, 58, 1546-1571. [CrossRef]

33. Statistics on the Number of Private Enterprises in China. Available online: http://www.chinabgao.com/k/ qiye/37764.html (accessed on 28 January 2019). (In Chinese)

34. Morikawa, M. What types of companies have female directors? Evidence from Japan. Jpn. World Econ. 2016, 37-38, 1-7. [CrossRef]

35. Withisuphakorn, P.; Jiraporn, P. CEO age and CEO gender: Are female CEOs older than their male counterparts? Financ. Res. Lett. 2017, 22, 129-135. [CrossRef]

36. Christensen, C.; Raynor, M. The Innovator's Solution: Creating and Sustaining Successful Growth; Harvard Business Review Press: Brighton, MA, USA, 2013.

37. Chen, J.; Zheng, G. Innovation Management: To Win Sustainable Competitive Advantage, 3rd ed.; Peking University Press: Beijing, China, 2016. (In Chinese)

38. Cui, W.; Fu, Y.; Wang, W. Exploratory innovation and exploitative innovation and China manufacturing enterprise innovation performance-An Empirical Analysis Based on the survey data from the World Bank. Ind. Econ. Rev. 2017, 1, 45-54. (In Chinese)

39. Weijun, C.; Shuo, H.; Yu, F.; Wenjing, W.; Jialu, Z. Research on the open innovation behaviors and influencing factors of Chinese manufacturing enterprises-Based on the world bank survey data in 2012. Sci. Technol. Prog. Policy 2018, 35, 76-81. (In Chinese)

40. Xu, J.; Huang, Y. Gender identity and family performance in marriage and labor. Econ. Res. J. 2018, 53, 136-150. (In Chinese)

41. Yuanqiong, H.; Yun, C. Empirical study on the relationship between the size of senior management team and enterprise performance in uncertain environment-Based on the evidence of listed companies in China's manufacturing industry. Sci. Sci. Manag. S.E T. 2009, 2, 123-128. (In Chinese) 
42. Chen, X.; Gong, Z. DEA Efficiency of Energy Consumption in China's Manufacturing Sectors with Environmental Regulation Policy Constraints. Sustainability 2017, 9, 210. [CrossRef]

43. Faccio, M.; Marchica, M.-T.; Mura, R. CEO gender, corporate risk-taking, and the efficiency of capital allocation. J. Corp. Financ. 2016, 39, 193-209. [CrossRef]

44. Blazsek, S.; Escribano, A. Patent propensity, R\&D and market competition: Dynamic spillovers of innovation leaders and followers. J. Econ. 2016, 191, 145-163.

45. Van Engen, M.L.; Willemsen, T.M. Sex and leadership styles: A meta-analysis of research published in the 1990s. Psychol. Rep. 2004, 94, 3-18. [CrossRef] [PubMed]

46. Akerlof, G.A.; Kranton, R.E. Identity economics: How our identities shape our work, wages, and well-being. In Economics Books; Princeton University Press: Princeton, NJ, USA, 2011.

47. Bosma, N.; Hessels, J.; Schutjens, V.; Van Praag, M.; Verheul, I. Entrepreneurship and role models. J. Econ. Psychol. 2011, 33, 410-424. [CrossRef]

48. Heydemann, S. Institutions and Economic Performance: The Use and Abuse of Culture in New Institutional Economics. Stud. Comp. Int. Dev. 2008, 43, 27-52. [CrossRef]

49. Wu, X.; Chen, J.; Mei, L.; Liang, L. Gender Stereotype: The Threat or Opportunity for Female Innovators in Technological Innovation? Foreign Econ. Manag. 2017, 39, 45-60. (In Chinese)

(c) 2019 by the authors. Licensee MDPI, Basel, Switzerland. This article is an open access article distributed under the terms and conditions of the Creative Commons Attribution (CC BY) license (http:/ / creativecommons.org/licenses/by/4.0/). 